\title{
THE QUR'ANIC SEMIO-ETHICS OF NATURE
}

\author{
Elma Berisha*
}

\begin{abstract}
This article goes behind the semiotic stereotypes of western representations of nature and language, to track and discuss discursive limitations in an attempt to place these semiotic concepts within their Qur'anic paradigmatic context. A cursory literature review of Western semiotics suggests systematic bias towards conventional signs, at the cost of naturallyoccurring ones. Drawing on the work of U. Eco, J. Deely, J. Hoffmeyer and other prominent semioticians, as well as the Qur'an as a 'semiotician's paradise par excellence', I examine a more comprehensive notion of sign and its relevance as a potential epistemological bridge between nature and culture, between internal phenomenological realities and the external world. My argument is that even at this postmodern, advanced stage of semiotics as a more comprehensive and inclusive study field, the downplaying of the semiotics of nature and its communication value continues to run as a subtext of the process of secularisation. Thus, the ethical and religious meta-representations that come with nature are likely to be neglected, with further ecological implications. All these findings seem to suggest that there is a need to reconsider and review these matters in a much more comprehensive way, given that reflection on the natural signs is one of the major themes in the Qur'an, alongside the reoccurring message that the only way to attain true belief in the Creator is to think through signs.
\end{abstract}

Keywords: semiotics, signs, nature, signification, ayah, Qur'an, Saussure, arbitrary, communication, language, culture

\section{If We Wished, Everything is a Sign}

Closer to nature, closer to God, it is said. Or so it has been resounding in my ears for ages. It goes without saying that nature spellbinds us in numerous ways. One way that has easily got my attention is that we take for granted the 'natural' attributes in consumer products and services bombarding us from all sides. So pervasively positive is the 'naturalness' of things to our contemporary consciousness, that we convince ourselves that what we do, feel, think, consume or cherish are 'natural' and not otherwise. More often than not, once we perceive something as 'natural', we do not feel the urge to 'explain' it. Nature gives us peace of mind. The natural is a given. "The myths which suffuse our lives are 
insidious precisely because they appear so natural" says R. Barthes. "They call out for detailed analysis which semiotics can deliver." Natural is normal. By contrast, in a constructed space of human-made signs, one needs to be aware of boundaries and risks. These commercial structures pinpoint their own selves, with each building, brand or logo begging for attention. The longer it holds our attention, the more successful its marketing appeal. One may be tempted to argue that, in a strict, literal semiotic definition, such a humanly constructed juggernaut cannot be classified as a sign, as it is not 'representing another than itself'. ${ }^{2}$ Yet, it is still a sign: it stands for value, benefit, development, social status, certain ways of life, social inequality, vanity and more.

Not all human-made signs are of commercial nature. Most human-made signs are informational and indispensable to life as we know it. Typically, when we speak of signs the first thing that comes to our mind is the 'symbolic' type, those with a combination of shapes, inscriptions and drawings. However, in the formal sense of postmodern semiotics, signs are much more than that. Everything is potentially a sign. ${ }^{3}$ Signs include alphabetical letters and numerals, the sound of our voice, religious artefacts, traffic signs, QR codes and paintings, skyscrapers, digital gadgets, non-verbal gestures, emoji, to name a few. Human-made signs could come in physical and non-physical forms: in ink or colours, in sound waves or music, in mental concepts or bodily gestures. Hence, signification is vital to human existence since it underlies all forms of communication. Sign is the fundamental notion and vehicle of any meaning-making. It is what language consists of. It is how thinking itself is ultimately made possible. Signs are the building blocks of human culture. And ultimately, signification is a means of shaping our very human subjectivity. Signs are important precisely because they can mean something other than themselves. A sign is everything which can be taken as significantly substituting for something else. ${ }^{4} \mathrm{~A}$ sign is also defined as an event that 'generates in us the expectation of something else'. ${ }^{5}$ By being capable of "standing for another to some third party", signs enable relations between things, concepts and people, into far-ranging meaning-making networks. ${ }^{6}$ It is held that this fundamental integrating function of sign is enabled by a sign being in a triadic relation between representamen, interpretant and object. ${ }^{7}$

The bulk of the modern study of signs or semiotics, and especially in Europe, focuses upon humans and their relation to communication and cultural artefacts. It is generally stressed that, as of human-made signs, the merit of the study of semiotics is to make the invisible visible, the implicit explicit and the unspoken spoken. Semiotics interprets the implicit messages that are embedded in humanmade signifying artefacts and cultural tapestries, as in all sorts of texts, graphic designs, art, advertising, architecture, online and offline media, etc. Besides, it is widely held today that talking without words or nonverbal communication 
constitutes a significant chunk of our human communication. ${ }^{8910}$ In sum, sign reading is about decoding, unravelling hints and hidden references in textual layouts and other cultural patchworks. It involves subjective interpretation and is ultimately a so-called 'process of semiosis' or meaning-making. What it tells us is that deeper meaning behind the apparent surface of reality is not only possible but necessary.

All cultural artefacts or mentifacts are considered human-made signs distinct from naturally-occurring signs, or unmanned signs. In nature, smoke is a sign of fire; heavy clouds are a sign of coming rain; fever is a sign of underlying illness. Thus, formally speaking signs are classified into two: conventional signs (humanmade, cultural signs, artificial signs) and natural signs (naturally occurring signs, unmanned signs). It seems that the latter have historically and philosophically been downplayed. Natural signs are expressed and their patterns tackled through conventional signs; nevertheless, we do not regard the former one as capable of any communication. This is despite the fact that all our contemporary lives are built upon the decoding of natural signs. By definition all communications are made possible through signs and only through signs. Yet, we treat natural signs as some sort of raw material. This attitude runs deeper than it seems in our contemporary profane consciousness. I caught myself in this mental bias when, for instance, I attempted to inspect food items semiotically on a routine breakfast table. At first, the inclination was to count as signs only the written inscriptions explicitly conveying some information, like brand logo, date of production, nutrition details and so on, thus excluding the natural food items. On second thought, the latter would have provided as much valuable information, independently and on their own. In this case, not coming with inscribed 'seals' and 'logos', the plain white plates, the plain white table, the plain wooden seats, the branches of the tree hanging over the table, were not counted as signs. It so happened that after breakfast, the plain white plate revealed the restaurant brand logo, initially hidden beneath the vegies. And when the whole set was cleared, the table revealed a plastic label 'Exclusively for Our Customers Only'. This makes one think about the general expectations we have of the signs in nature. Perhaps they are supposed to be as explicit as these cited written illustrations, to be regarded as capable of communication value. On the other side, it seems like the semiotic skills needed to unravel deeper meanings are spared for the multi-layered connotations of human-made signs, while we ignore the natural context and natural signs in the latter. As Merleau-Ponty notes, we learn to see. We only see in the world what we have learned to see through habits of seeing. ${ }^{11}$ Natural signs as 'signs', more often than not, fail our daily attention threshold. In the context of consumer trust, it is less likely that attention will be paid to what something stands for or what it has to say. While this could be a layman tendency, 
it is worth surveying the historical record of the scholarly discourses alongside this cut-off line between human-made signs and naturally occurring ones.

\section{The Lost Heroes}

A cursory literature review suggests that almost until the $21^{\text {st }}$ century, Western philosophical thought was characterised by a gross limitation of sign doctrine. ${ }^{12}$ Human-made signs were the subject matter of semiotics enquiry per se. 'Nothing is a sign unless it is interpreted as a sign' ${ }^{13}$ Humans decide what a sign is, what is signal and what noise is. All meaning is in us and according to us. We decide what is a sign, fact, theory, myth, noumenal, animistic, or astrological. According to J. Deely, ancient Greece dealt with signs only in terms of 'medical symptoms' rather than as a worthy subject of philosophical inquiry. 'Semeon' was the original Greek word for sign. ${ }^{14}$ It was Umberto Eco who first suggested that, despite ancient Greek sophistication in logic, grammar and rhetoric, they did not have a notion of general signs as comprehensively understood today. ${ }^{15}$ Meanwhile, it is said that, when Saint Augustine in the $4^{\text {th }}$ century CC elevated the concept of signs within the domain of philosophical scrutiny, he left the natural signs out, promoting conventional signs only. ${ }^{16}$ During the Middle Ages, Europe was full of human-made signs and symbols that highly correlated with religion and ancient superstitious practices. ${ }^{17}$ 'Everything was meaningful' and according to Eco, Europe's medieval civilisation attempted to "assign a symbolic meaning to every piece of the furniture... ${ }^{18}$ However, it is generally implied that in between the work of Saint Augustine and the $17^{\text {th }}$ century, there was an utter void in the field of semiotics of nature. Just like in almost any other discipline, the contributions of Islamic civilisation remain unaccounted for, either due to language barriers or because they are typically downplayed as irrelevant.

There are too many historical insights on this matter for justice to be done in the limited space. Suffice to say that there are many missing 'natural' semioticians or proto-semioticians of nature, whose contributions seem to have been neglected by mainstream narratives. In many accounts, author after author fails to mention them, while only the contributions of some are brought to light by others. J. Deely, an important contemporary scholar of semiotics, has much to say about the lost work of Poinsot, a Latin semiotician from the $17^{\text {th }}$ century. He laments the loss to humanity caused by Poinsot's work having been put on the shelf of oblivion for 4 centuries. According to him, Poinsot developed at length the doctrine of semiotics of nature, on top of conventional signs as conceived earlier by St Augustine. Another hardly mentioned name in the historical stream of semiotics is Saint Bonaventure, from the $13^{\text {th }}$ century. A couple of years ago when I translated a book by the Malaysian scholar Syed Muhammad Naquib al-Attas, I 
recall vividly his emphasis on the neglect of Saint Bonaventure's work in western mainstream philosophy! Clearly, Al-Attas was not lamenting it from a semiotic perspective. His point was to showcase the loss of a potential alternative stream in Western philosophy that would have perceived nature in a different light. St. Bonaventure was one of those who espoused approaching to nature as an 'Open Book', a concept that Prof Al-Attas suggested might have been inspired by Holy Qur'an, its Latin translation having been in circulation in Europe at that time. ${ }^{19}$ In hindsight, if this suggestion rings with facts, then there could have been more of such proto-semioticians who took the sign doctrine in a holistic perspective, encompassing both types of significations, human and natural. Indeed, to my surprise, not only were there more missing heroes, but both the Saussure dyadic model of signifier and signified, and the highly celebrated tripartite model of Peirce, seemed not to have been $20^{\text {th }}$ century, after all. ${ }^{20}$

With the emergence of the Enlightenment, it is held that natural signs were finally preferred and promoted, says Cobley (2010). Due to an emphasised belief in reason and rationality, 'the natural' was valued over 'cultural'. With this, the human-made symbols were construed as unnatural or artificial. This was a tendency stemming from a more general cultural milieu that drew upon unfolding scientific achievements of the day, rather than semiotics as a formal discipline, which was still by and large limited to the conventional realm. If we classify cultures based on the way they conceptualise signs, ${ }^{21}$ a pattern is likely to emerge. However, in a broader sense, in juxtaposing conventional signs against the natural, the vested interpretations are inconsistent and contradictory. Particularly, it is pointless to assume that one or the other is a more 'rational' approach. It is clear that irrational interpretations can be potentially imposed on both types of signs, conventional and natural, but this is another topic altogether.

\section{The Qur'anic Creative Impulse}

In Classical Islamic societies, the cultural emphasis was more on natural signs, which in turn, tipped over the opposite end of the scale. An obsession with the 'natural world' gave a lasting boost to all sorts of experimental sciences. The renowned scholar Mohammad Hashim Kamali, in an article entitled "Reading signs: A Qur'anic Perspective on Thinking", cites Muhammad Iqbal and Malik Bin Nabi as among many scholars who forcefully attributed the efflorescence of science in Muslim societies to the "creative impulse of Qur'an." 22 This was fulfilled when Muslim thinkers departed from the approach of deductive thinking to a new dawn of sign-based thinking, predicating empirical experimentation and inductive reasoning. The Holy Qur'an, which was part of daily obligatory recitations, spoke explicitly of 'signs' in nature. The Qur'an taught an essential 
doctrine of the ayat (God's signs in the universe) functioning as pointers to the providential purpose at all levels of creation. The word ayah and its plural ayat occurs in the Qur'an over 400 times. Indeed, the Qur'an introduces itself as a collection of ayat. ${ }^{23}$ It indicates that God revealed the truth in nature by allusion through the modality of signs and it therefore, urges observation of and reflection on nature. Moreover, it reiterated that the only way to attain true belief in the Creator was to think through signs. Invocation for reflection over signs in nature is as prominent in the Qur'an as invocation to reflect over the signs of the Text, the revealed Holy book itself. ${ }^{24}$

To quote Netton (1989) on semiotics of nature, the Qur' an "may be described as a semiotician's paradise par excellence"25: "And how many a sign within the heavens and earth do they pass over while they, therefrom, are turning away" (12.105). "And Allah sends down rain from the skies, and gives therewith life to the earth after its death: verily in this is a Sign for those who listen" (16.65). "And [He has subjected] whatever He multiplied for you on the earth of varying colours. Indeed, in that is a sign for a people who remember" (16.13). "And We have left thereof an evident Sign, for any people who (care to) understand" (29.35). "And of His signs is [that] He shows you the lightning [causing] fear and aspiration, and He sends down rain from the sky by which He brings to life the earth after its lifelessness. Indeed, in that are signs for a people who use reason" (30.24). "And of His signs is your sleep by night and day and your seeking of His bounty. Indeed, in that are signs for a people who listen" (30.23). "Then, has it not become clear to them how many generations We destroyed before them as they walk among their dwellings? Indeed, in that are signs for those of intelligence" (20.128). "With it He produces for you corn, olives, datepalms, grapes and every kind of fruit: verily in this is a sign for those who give thought" (16.11). "Do you not see that ships sail through the sea by the favour of Allah that He may show you of His signs? Indeed, in that are signs for everyone patient and grateful" (31.31). "And a sign for them is the dead earth. We give it life and bring out of it grain, so they eat from it" (36.37). "Then, do they not look at what is before them and what is behind them of the heaven and earth?...Indeed in that is a sign for every servant turning back." (34.9) ${ }^{26}$

Kamali interprets the verse "We shall soon show them our Signs in the universe and in themselves..." (41.53) as evidence that signs in the universe may not be instantaneously visible nor readily available. Rather, they require a certain amount of intellectual and empirical striving to be grasped. ${ }^{27}$ It is precisely this aspect of partial lack of immediate availability to sense-perception that defines the function of signs. Nature as a signifier points towards its divine origin by virtue of the Transcendental Signified Being incomprehensible to mortal senseperception. While advancing his notion of sign-function, among others, Eco 
illustrates such a prerequisite with a specific example. To him 'smoke is only a sign of fire to the extent that fire is not actually perceived along with the smoke'; implying that the moment fire becomes visible alongside the smoke, the latter one loses the function of a sign. ${ }^{28}$ The Holy Qur'an, in crowning nature as a signfunction of its Maker, stretches the sign-spectrum towards infinity. So rich is the Qur' anic sign-weaved tapestry that the spectrum of phenomena qualified as signs is unlimited. There is reference to signs as natural phenomena $(36.37,36.33)$ as well as supernatural phenomena $(26.4,17.59)$; signs as warnings $(17.59)$; signs as blessing (16.11); signs as punishment (43.48); signs as a feast of celebration (5.114); signs as tongues (30.22); signs as text (16.101); signs as historical events $(10.92,29.15,27.52,30.58)$ and artefacts $(2.248)$; signs as inherited knowledge (26.197); and signs as technology (36.41); signs as communications (10.10) and signs as human beings $(21.91 ; 23.50),{ }^{29}$ to name a few. Thus, signs seem like the 'theory of everything'. Without any enforced top-down framework, readers of the Qur'an are invited to wholly observe, travel, explore, experience, test, infer and have their own unique way of interacting with signs. Approximately 750 verses, or nearly one-eighth of the Qur'an, exhorts the readers to study nature, history, the revealed Text, and humanity at large. Reflection on naturally occurring signs is one of the key major themes in the Qur'an, alongside the invocation to reflect on the Oneness of God. Invocation to reflect on historical precedent and humanity which by far encompasses human culture is another key theme. This clearly is a call to transcend sense-perception and dwell in the intellectual and empirical explorations of natural signs. As Kamali succinctly put it, even among mostMuslims scholars obsessed with Greek philosophy, it took time to realise that in bringing this crucial nexus of connection between human thinking and nature, the Qur'anic spirit was ultimately anti-classical. ${ }^{30}$

Amid classical Muslim societies of golden age, the linguistic and other humanmade signs and symbols occuring in the formalised languages of science, textual analysis, architecture and art were anything but neglected. A highly sophisticated literary culture and book industry boomed to an unprecedented scale. ${ }^{31}$ In the popular imagination, the ink of the learned people was regarded as sacred and the pen was seen as the first thing to have been created by God. So it is hard to say, for instance, which of the signs in that era, the human-made or the naturally occurring, got more attention. Culture and nature were in a healthy symbiotic relationship, which was reflected, for example, in the nature-friendly Islamic architecture of the time. ${ }^{32}$ This is very different from today's popular Islamic discourse, preoccupied with 'signs of the apocalyptic times'. 


\section{'Saussure Wanted to Have it Both Ways'}

F. de Saussure was the founding father of semiotics as a distinct field in the $20^{\text {th }}$ century. His name and semiotics are almost inseparable. He was, however, a linguist and it is said that he himself did not write anything in semiotics. His students gathered notes from his lectures and published them posthumously. $\mathrm{He}$ is famously said to have urged for a new science "that studies the life of signs within society." ${ }^{33}$ When I started looking at semiotics, I had a few preliminary 'un-semiotic' queries. I was unknowingly looking for what in Peirceian terms is defined as 'indexical' signs. Besides, when I started dwelling on those queries, I was not aware that semiotics existed as a comprehensive field of independent study, as profoundly espoused by J. Deely, U. Eco, J. Hoffmeyer, J. Lotman and others. ${ }^{34}$ However, from day one in my earliest readings I took issue with Saussurean's concept of arbitrariness blanked over the whole field of sign systems. I found no element of 'nature' in the Saussurean model of signs. To him, signs were linguistic. He shunned 'symbols', as he regarded them as too complicated. ${ }^{35}$ Moreover, for Saussure a linguistic sign was arbitrary; a relation between signifier and signified was arbitrary; a relation between signs itself was arbitrary. ${ }^{36}$ And, although signifier was a material substance (ink for written sign or sound for spoken sign), the signified was a simple mental image, nothing to do with the objects in the external world. Thus, communication between humans was seen as possible without any reference to the real world, simply by verbal exchange of the contents of the mind. There is an infinite repository of potential spoken or written signifiers, and on the other side, with our mind full of mental signifiers, we exchange them and that's how we communicate. That's how we create and exchange meaning. Everything is arbitrary and meaning is derived by spotting the difference between the signs. The objectivity of the signs does not reach further than the ink on the paper or the sounds waves in the air.

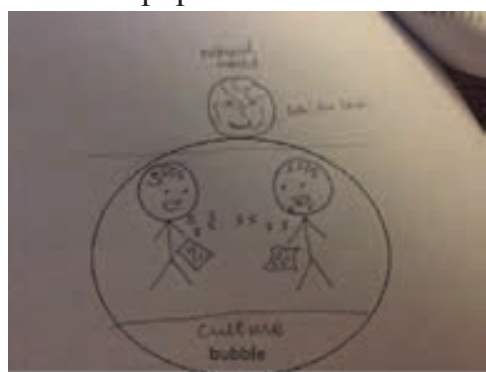

Although my meagre exposure to linguistics allowed me no 'degree of freedom' to delve into these linguistic entanglements between nature and nurture, it certainly sparked more questions. Simply, is the arbitrary difference between linguistic signs sufficient to make the signs work? To put it semiotically, is there 
really "no fullness in presence, only difference" ${ }^{37}$ ? The notion of difference, although certainly useful in sprouting the structuralist discourse in the Saussurean century, may not be sufficient in itself. Above all, it cannot be the only way to derive meaning out of signs. If it were, then we should be able to speak all languages because all languages are 'different'! Without a learning process, however, that is not possible. Learning itself relies on experience rooted in the natural and social world. To learn a language just by relying on conventional signs is not feasible. Time and again, we need to associate words with images and real objects or events from the external world for learning to occur, until one masters the tongue and uses it as an anchoring reference of arbitrariness.

Thus, is there anything 'natural' underlying the arbitrariness? J. Lacan insisted that the linguistic system is 'outside' the human subject and the user is separated from the system of signs. He held that there is no intrinsic difference between mental concepts prior to connection and experience with signifiers. For Saussure, we have these pure mental concepts in our mind's repository; we add a 'name' later. ${ }^{38}$ Signifiers may construct our mind-set, mould our subjectivity, limit and distort our thinking and imagination, but they do not precede us. Like our trusted brands of choice, how far back in time do they reach? Moreover, mental concepts after experience with the external world are prone to modification and that should be a good thing. Thus, putting aside my personal prejudices on 'arbitrariness', I ponder on the developmental patterns of writing systems, from ancient pictographic ones to today's digital binary code. Arbitrariness is a wondermaking tool once it has been set in motion. Nevertheless, it fundamentally needs a zero year in its lifespan calendar. The Holy Qur'an tells poignantly how "We taught Adam the names." $(2: 31)^{39}$ Even though human nature must have been suitably pre-moulded as a 'receiver', the filling therefore seems to have been done externally. A learning process happened, an exchange with the outside. The Bible goes even further by saying that God brought all things, one by one, to showcase to Adam and associate each with its corresponding name (II:19). ${ }^{40}$ The zero year may be unknown, but one must be. Without some point of origin to anchor the arbitrariness, language as an unnatural phenomenon, purely learned, a product of social learning, remains unconvincing. Moreover, if association between signs cannot be arbitrary, as it would not generate any meaning, then the association within signs may not be arbitrary either. The problem of anchoring the arbitrariness may be illustrated from the opposite end, when Derrida was pondering how to 'halt' the never-ending process of difference into a meaningful sentence; or Peirce and Eco were wondering how to conclude the infinite semiosis'. ${ }^{41}$ According to J. Deely, when F. de Saussure attempted to revive the concept of sign, he wanted it both ways: to revive the notion of sign and yet, to leave the natural out. ${ }^{42}$ 
Cobley \& Jansz illustrate how later on, for Soviet semioticians of the 60s and 70 s, language was seen as the primary modelling system for human knowledge and interaction. Culture was the 'secondary modelling system'. In a multitude of ways, however, they both shaped human subjectivity. Y. V Ivanov is quoted: "Possession of natural language and the sign systems constructed upon it is the specific particularity of man." ${ }^{\text {"33 }}$ It follows that later developments came to advance in considering the non-verbal language as a primary modelling system, meaning even closer to 'nature'. Accordingly, there is a tendency among these Soviet semioticians to consider the language as 'natural language'. On the other side, Saussure implies a 'high point of rationality' because he considered the nature of linguistic signs as 'unnatural' or 'arbitrary'. Like in all other dichotomies that try to simplify the complex interactions between nature and nurture, or juxtapose it as mutually exclusive, there is a fallacy in this. Departing from rationality or communicative value any naturally occurring supra-individual phenomena, which precede the individual, is part and parcel of this over-simplification. Anything defined as an un-arbitrary sign implies lack of human agency, which in turn necessitates an ontological explanation. Hence, it is to be avoided. Yet, it is so contradictory, because it seems that the more non-arbitrary a phenomenon is, the more deep-rooted its causality in nature is, the longer it has been around and the higher is the trust invested in it.

In his 'A Theory of Semiotics', Eco (1976) on the very first page systematically define what a sign is and what is no. This included which of the naturallyoccurring signs were to be counted as signs and which were not, in accordance with certain well-defined criteria. He also reiterates the very basic tenet that "a Saussurean sign demands to be intentionally emitted and artificially produced." 44 Nevertheless, going beyond this, Eco maintains that "it is possible to interpret Peirce's definition of sign in a non-anthropomorphic way." ${ }^{45}$ Thus, the Peircean triadic sign can also be applied to "phenomena that do not have a human emitter, provided that they do have a human receiver." symptoms can fall under the category of 'signs' proper. In order to offer a more solid platform to make this definition work, Eco makes in advance a cut off line definition between communication and signification. What Eco suggests is that it is possible to have signification without communication, but not the other way around. This could be understood as entailing that there are signs which do not communicate, but there cannot be communication except through signs. A 'receiver' (interpreter) is necessary but a 'sender' is not for a sign-function to be established properly. For naturally-occurring symptoms and indices to be signs, a 'sender' is not needed (by definition). Indeed, if a 'sender' were needed by 
default, which is not the case according to this definition, then these would not be signs. They would rather be anthropomorphically downgraded to the Saussurean dyadic level of arbitrary conventionality of sender-receiver communications. Hence, when dealt with only at the level of communication, any naturallyoccurring signs cannot be counted as signs! In such a maverick nutshell, Eco contends that semiotics is about signification and not about communication. Hence one can easily infer that, although it cannot be denied that nature embeds signs in it, it is not to be taken as 'communicating anything' since the semiotics theory is not about communication. Yet, if we postulate that semiotics is only about communication, then we cannot include these as signs proper because they fall short of the standard Ecoan definition. Thus, nature has nothing to say, either way, although it may still be signifying.

Besides, Eco adds 'social rule' as a criterion to qualify something as a sign. Every time a human group decides to use and to recognise something as the vehicle for something else, there is a sign. So, ultimately it is the humans who decide conventionally what is a vehicle for something else, based on a social rule! Nevertheless, this is a bit far-fetched on a qualification criteria when it is obvious that normally humans do not make social rules for everything encountered or potentially encountered. The spectrum of signs in nature is so far-ranging that to make available a social rule for all of them is not plausible. Usually, it is the theoretical inputs of the human mind that attempt to catch up with reality rather than the other way around. At the same time, this also implies that, if humans of a certain era decide that something is not pointing beyond itself, then that would not be a sign. Therefore, in that specific case, there is no receiver of the coded message and, even more importantly, there is no sender to be connoted or inferred. Instead of deducing intentionality based on natural signs, a few humanmade criteria are added to infer non-intentionality and absence of any 'sender'. Yet, later on in the book, Eco cannot help but refer to cases when semiotic phenomena seem to arise from non-semiotic phenomena, and describes it "as a sort of 'missing link' between the universe of signals and the universe of signs." ${ }^{\text {47 }}$

\section{Is it Even a Junction?}

That there is a perceived unbridgeable divide between nature and culture is an open secret. This is a gap between what is man-made and what is ready-made. My memory is vivid with my reaction to my first 'scientific exposure' that our bodies contain acid chemicals or metals like iron, zinc, copper or phosphor and so on. As pupils in chemistry laboratories, we were reminded to take precautions to 
protect our eyes or skin. It was not easy to fathom that the acids inside the human body, by contrast, are essential for human life! Acids are necessary for digestion, genetic coding, production of proteins and hormones, energy production and so on. This is just a case in point, as is the electric nature of human thinking itself. A fine line or an illusory boundary is imposed between external nature and our human selves, or our internal bodily environments. This is yet another way of denying natural signs, this time inside our own selves.

Conventional semiotics suggests that we are usually desensitised to the cultural signs that surround us. Like fish in water, we are oblivious to them. Thus, the mission of semiotics is, in a sense, to make us aware of the water around us. It's about making us see beyond what appears to be, beyond the surface. If we extend this notion further, as has already been done in $21^{\text {st }}$ century mainstream semiotics, assuming that nature is not communicating to us is tantamount to reading denotations as if they are without connotations. It is literalism in an arrogant sense. It is as if we are saying there is only one way of communicating and that is through words, despite the proliferation of a wide range of modern disciplines and studies on gesticulation and non-verbal forms of communication. ${ }^{48}$ With the advancement of science and technology, examples like the realm of genetic material, as non-conventional coded material, is undeniably about communication. It enables communication across organisms, through time and space. As wonderfully espoused in Hoffmeyer's bio-semiotic approach, our very lives depend on these processes of semiosis, being part of our biology, at all levels of physiological interactions in and between organs, tissues, cells and intracellular communications. ${ }^{49}$ According to Hoffmeyer, life is survival in coded form. 'Heredity is semiotic survival'. ${ }^{50}$ Genetic material contains a 'coded description of how to construct an organism'. ${ }^{51}$ Moreover, "of all the creatures on this Earth only the fertilised egg is capable of reading this code and translating its message into an organism.." ${ }^{2}$ Hoffmeyer, quotes the work of F. Stjernfelt in warning against the denial that "human signs have sprung from a natural world and thus denying that there could be anything in nature bearing any resemblance to human signs." ${ }^{, 3}$

As hinted at earlier in this article, nature's products are actually much 'smarter' when it comes to meeting the needs of our bodies. In fact, most of the good things humanity knows of are learned from nature. Perhaps nature has been 'silently' telling us something with its existential being, by being part of our very own bodily architecture. On the outside, there are monumental buildings that speak to us more than any human being ever has. But that is fine, because that is a human-made sign, an exquisite design which we 'get'. Saussure started with semiotics as something that has to do with words and language. But, it seems like the biggest role that semiotics has had to play in our postmodern 
consciousness is its ability to unravel the non-verbal side of communication, or that which is meant but fails to be said, or fails to be noticed. Things that are expressed in other ways, in ways that are in fact much more difficult to be concealed or withheld unexpressed. In the words of P. Watzlawick "One cannot not communicate." ${ }^{54}$ So too with nature: nature 'cannot not communicate'. And if and when it 'arbitrarily' ceases to do so, at the individual level, our language skills will cease to be of use.

\section{Semiospheric Footprints}

Saussure's signs are purely psychological and arbitrary. Each sign is defined by being counter-positioned to others within a closed system. However, with Peirce the concept of sign goes beyond the linguistic phenomenon. Peirce stood for the realisation that the whole "universe is perfused with signs." 55 Juri Lotman introduced the concept of 'semiosphere' as the totality of all human sign systems. Thomas Sebeok, a student of Peirce, was the pivotal figure whose work became instrumental in bridging the gap between fragmentary streams of semiotics and its diverging tendencies. ${ }^{56}$ Sebeok's work transcended the predominant paradigm of behaviourism and led to a semiotics beyond the confines of human phenomena. He talked about signs in terms of 'definition of life'. ${ }^{57}$ Sebeok's understanding of semiotics was comprehensive, exhausting the whole spectrum of the sources and channels of signs, being organic and non-organic, material as well as energetic. When he outlined all potential sources of signs, it became apparent that anthroposemiosis of human-made signs is only a small part of the whole network. Besides, it acknowledges that the semiotic input and output in humans goes way beyond linguistics, being rooted as much in natural surroundings as in cultural surrounding. His elaboration of the concept of 'umwelt', originally coined by Jacob von Uexkull, a German biologist, was used to contextualise the process of semiosis. In sum, as every organism gives clues about the nature of its habitat, every organism acts as a sign. In turn, the habitat is also a sign for the organism because it is possible to make inferences about the latter based on analysis of its natural habitat. ${ }^{58}$ Thus, nature inadvertently gives clues about its processes and organisms, about us, about its Maker. But while the cultural environment speaks aloud, particularly today with its commercial and scandalous media, nature continues to remain silent, although perhaps not for long. Enter the ecological disaster lurking behind the corner and the need for revisiting our wrong-headed patterns of civilisational becomes apparent.

Natural signs are the raison d'être of semiotics. Otherwise, it would have remained as it was, linguistics. Saussurean semiotics was nominalist; it is not possible to get to the world of the real because all that comes to us is mediated by signs. But to Peirce, Eco and Sebeok, to name just a few prominent semioticians, 
even though the process of getting to the 'real' is arduous, it is still possible. In the thread of Western mainstream thought, while philosophically the existence of nature has yet to be verified, practically it has been dissected as much as possible. Deely speaks at large about Western philosophy playing the Mr. Hyde to science's Dr Jekyll, and explains at length how it came to be so. ${ }^{59}$ Modern science took a course of its own, having its own utilitarian and pragmatic objectives, officially with a 'control and predict' approach. It fits well to resume with the paradigm of Nature the Mute, because that facilitates the wrathless exploitation of nature, in pace with the accelerating drums of global consumerism and commodification. Thus, in a way, the 'problem of the external world', persistent over the centuries of Western philosophy, from Descartes to Kant and beyond, ${ }^{60}$ has now become a concrete problem in the shape of climate change and global warming. The debate of mind-dependent versus mind-independent nature has now taken the form of human-caused versus naturally-occurring climate change. ${ }^{61}$

In between philosophy and science (not to mention politics), Hollywood has finally taken action. Some of its top stars have joined voices to give nature a voice. 'Nature is Speaking' is Conservation International's 'invitation to human race to listen to nature'. Initially published on October 5, 2014, Julia Roberts, Harrison Ford, Kevin Spacey, Edward Norton, Penelope Cruz, Robert Redford, Ian Somerhalder and many more joined the platform speaking on behalf of nature. "Some call me nature. Others call me Mother Nature. I've been here for over 4 and half billion years... whether you regard or disregard me does not really matter to me, one way or the other, your actions will determine your fate..." ${ }^{62}$ goes the voice of Julia Roberts. This has been commented on as a 'frontal critique of the residue of thousands of years of Western thought alleging human dominion over the earth as nature's special species in full entitlement'. The Hollywood voice of Nature is urging us to look around and humble ourselves, just like the Holy Qur'an has done for ages, to compromise our human narcissisms and egotisms for a broader social solidarity, viable material sustainability as well

as a spiritually balanced psychology, to be appreciative, to be responsible. But many a time when I look around in our modern living habitats, I see only but advertisements. In regional flights, when in and out of aircraft, or when looking outside the window prior to taking off, lately one can notice the aircrafts in a row flashing ads all over their exterior. Ironically, it seemed to me as if, after losing our ability to lend an ear to nature and upon squandering its natural goods, in our consumerist thrust we have started to advertise to it.

\section{Semiotic Bubbles}

Signs not only represent reality to the degree that we allow, signs construct our 
reality. Signs are both physical and mental indications which, in the semiotic tradition, are taken to produce human subjectivity. ${ }^{63}$ For as much as they provide the only window to the world, they also taint it, blurry it or distort it. At times, the meaning we create from a sign could simply be a thrill of our mind. 'They are but names which ye have named' (53.23). ${ }^{64}$ This unique function of signs, to stand for something else, is a double-edged sword. It could be construed to mean signs are baseless and have no bearing on reality. A culture that distances itself too much from nature or denies a healthy relationship with it, self-sufficient in unilateral human-made communications and meaning-making systems, may not be sustainable in the long run. That resembles a house of cards that may be falling apart at our next turn. John Kay's description of our self-made financialised economies which have in fact necessitated the coinage of 'real economies', is a case in point. ${ }^{65}$ Here is where our human-made semiotic means reached their apex, aided by most sophisticated computer quantified logarithms, detached from the real world. The stock markets have taken on a life of their own, Kay says. Good knowledge of market players does no good in approximating good returns. What 'markets' 'think' about those players makes or breaks it because everything moves according to the semiotic cues of others, not the real world.

Semiotic resources have outpaced natural resources. In the digital age, adding a virtual layer to all of this is not likely to make things more real. Seeing the world through the 'fake news' filter of social media is already becoming a major concern for most serious policy makers, empowering the 'post truth' paradigm, as witnessed at the end of last year. In recent decades, a distinct field of multimodal semiotic studies has emerged, working on the principle that technology has further boosted the range of human linguistic and non-linguistic semiotic resources. Digital technologies have significantly expanded the range of media by which humans can engage in meaning making. Multimodal texts include audio-visuals, documents, websites, social media, 3D objects, interactions, events, etc. The challenge is how to capture a particular thread of semiosis running through these concurrent linguistic and non-linguistic platforms ${ }^{66}$ The irony is that, despite this significant achievement in the multi-modal nature of communications, in between technology and culture, the semiotics of nature is again likely to fall in between the cracks.

\section{Key Recommendations}

- Signs not only represent reality, the way we read signs also constructs our reality. A renewed worldview transcending fallacious dichotomies and balancing its essential aspects alongside nature and culture, material and spiritual, mandates a return to the original Qur'anic doctrine of thinking 
through signs. Establishing a contemporary Islamic theory of signs rooted in elaborated Qur'anic concepts could have both theoretical and practical implications, particularly for our understanding of and relation to nature. It could also promote a new order of relationship between the natural sciences and humanities. ${ }^{67}$

- The new discipline would unearth the semiotic treasures in Islamic literature treasure, that have existed for ages but have nevertheless not been framed as 'semiotic' given that the term is recently-adopted even in Western thinking. Semiotic content and tools cuts across innumerable fields, such as logic, linguistics, grammar, semantics, cognition, philosophy, anthropology, natural sciences, to name a few. The work of Muslim scholars that falls nothing short of semiotic analysis in the strictest sense, could be highlighted and integrated into a common discourse. ${ }^{68}$ This is not far-fetched given that even 'Semiotics' as a comprehensive contemporary discipline, independent from philosophy and linguistics, is itself recent. 'Cognitive Semiotics', for example, a field that is attempting to bridge the gap between the sciences and the humanities, only emerged as late as the 1990s.

- Nevertheless, the main objective would be to rediscover and reclaim the semiotic approach as an epistemic method and paradigmatic framework, rather than highlight the past. This new discipline could shed light on the influence Qur'anic discourse had on the development of Western semiotics, particularly during the European Renaissance.

- Re-reading Islamic traditional texts using Western semiotic tools may produce a great many new suggestions. But, it may well prove counterproductive and misleading, as it already has in many cases. ${ }^{69}$ Thus, establishing and promoting authentic Islamic semiotic methodologies and tools is necessary, even within the limited domain of Islamic hermeneutics.

\section{Notes}

* Elma Berisha is an alumni of the International Islamic University Malaysia. She is a social researcher, psychologist by training, data scientist by profession, with a recent research interest in cognitive semiotics. In the past decade, Elma has worked with a wide spectrum of public institutions in Malaysia, including top universities, international organisations and professional bodies. Until 2015, Elma was the Regional Manager for Consumer Research in Asia Pacific, with Frost \& Sullivan. Her focus research area was on the evaluation of public perceptions in Malaysia and Singapore, primarily monitoring issues of public safety, corruption and urban development. Currently, Elma is attached to the Asian Institute of 
Finance, a Bank Negara think tank in Kuala Lumpur established to enhance human capital development.

1. Paul Cobley and Litza Jansz, Semiotics, A Graphic Guide (London: Icon Books Ltd, 2010), 46.

2. John Deely, 'A Sign is What? A Dialogue between a Semiotist and would-be Realist,' The American Journal of Semiotics 20, no. 1-4 (2004): 32.

3. Umberto Eco, A Theory of Semiotics (London: Indiana University Press, 1976).

4. Ibid., 7.

5. Deely, 'A Sign is What?', 40.

6. John Deely, 'The word semiotics: Formation and Origins,' Semiotica 146 (2003); 2 .

7. Jesper Hoffmeyer, Signs of Meaning in the Universe, trans. Barbara J Haveland (Bloomington \& Indianapolis: Indiana University Press, 1996).

8. Jordan Zlatan, 'Cognitive Semiotics: An emerging field for the transdisciplinary study of meaning,' The Public Journal of Semiotics 4, no.1 (2012): 2-24.

9. D. E. O'Leary, 'Big data, the internet of things and the internet of signs,' Intelligent Systems in Accounting, Finance and Management 20, no. 1 (2013): 53-65.

10. Eco, A Theory of Semiotics.

11. Maurice Merleau-Ponty, Phenomenology of Perception, trans. C. Smith (London: Routledge \& Kegan Paul, 1962).

12. John Deely, 'The Impact of Semiotics on Philosophy', Prepared for the First Annual Hommage Oscar Parland at the University of Helsinki, University of Helsinki (2000). Available at: http://www.commens.org/sites/default/files/ news attachments/greenbook.pdf (Accessed: 22 February 2017).

13. Inna Semetsky, 'Peirce's Semiotics, Subdoxastic Aboutness, and the Paradox of Inquiry', Educational Philosophy and Theory 37, no. 2 (2005): 232.

14. Deely, The Word Semiotics.

15. Umberto Eco, 'At the Roots of the Modern Concept of Symbol,' Social Research 52, no. 2 (2015): 383-402.

16. Deely, The Impact of Semiotics.

17. Cobley and Jansz, Semiotics.

18. Eco, At the Roots of the Modern Concept, 394.

19. Syed Muhammad Naquib Al-Attas, Islam and Secularism (Kuala Lumpur: International Institute of Islamic Thoughts and Civilization, 1978).

20. See the following references for a brief indication that the dyadic and triadic sign models chronologically precede the much celebrated contributions of $20^{\text {th }}$ century semiotics: Stephan Meier-Oeser, Medieval Semiotics, The Stanford Encyclopedia of Philosophy (Summer 2011 Edition), available at: http://plato. stanford.edu/entries/semiotics-medieval/. (Accessed on: 24 February 2017); Doria Charles, 'Another Page in the Foundation of Semiotics', A Book Review of On the Composition of Images, Signs and Ideas (1591), by Giordano Bruno (New York: Wills, Locker \& Owens, 1992). Available at http://www.nadin.ws/ wp-content/uploads/2007/03/another_page.pdf (Accessed December 15, 2017); Hoffmeyer, Signs of Meaning.

21. Cobley and Jansz, Semiotics. 
22. Mohammad Hashim Kamali, 'Reading the Signs: A Qur'anic Perspective on Thinking,' Islam \& Science 4, no.2 (2006): 152.

23. Ibid.

24. Malik Badri, Contemplation: An Islamic Psychospiritual Study (Kuala Lumpur: International Institute of Islamic Thought, 2000).

25. Ian Richard Netton, Allah Transcendent, Studies in the Structure and Semiotics of Islamic Philosophy, Theology and Cosmology (London \& New York: Routledge Taylor \& Francis Group, 1989), 321.

26. The Holy Qur'an.

27. Kamali, Reading the Signs.

28. Eco, A Theory of Semiotics, 17.

29. The Holy Qur'an.

30. Kamali, Reading the Signs.

31. Ziauddin Sardar, Islam, Postmodernism and Other Futures: A Ziauddin Sardar Reader (London: Pluto Press, 2003).

32. Seyyed Hossein Nasr, Traditional Islam in the Modern World (Kegan Paul International: 1990).

33. Ferdinand de Saussure, Course in General Linguistics, ed. Charles Bally \& Albert Sechehaye (New York, Toronto, London: McGraw-Hill Book Company, 1966), 16.

34. Zlatan, Cognitive Semiotics.

35. M. Morrell, 'Signs and Symbols: Art and Language in Art Therapy,' Journal of Clinical Art Therapy 1, no.1 (2011): 25-32.

36. Cobley and Jansz, Semiotics.

37. Netton, Allah Transcendent, 323.

38. Cobley and Jansz, Semiotics.

39. The Holy Qur'an.

40. Martin Lings, Symbol and Archetype, A Study of the Meaning of Existence (Cambridge: Quinta Essentia, 1991).

41. Hoffmeyer, Signs of Meaning; Deely, The Impact of Semiotics.

42. Deely, The Impact of Semiotics.

43. Cobley and Jansz, Semiotics, 139.

44. Eco, A Theory of Semiotics, 15.

45. Ibid 15.

46. Ibid 16.

47. Ibid 21.

48. Zlatan, Cognitive Semiotics.

49. Hoffmeyer, Signs of Meaning.

50. Ibid. 24.

51. Ibid. 16.

52. Ibid. 16 .

53. Ibid. 78

54. Peter Muijres, The five axioms of communication (Watzlawick) - with a few cultural notes, Available at https://cultureclassblog.wordpress.com/2014/12/31/ the-five-axioms-of-communication-by-watzlawick/. (Accessed January 15, 2017).

55. Semetsky, Peirce’s Semiotics, 232. 
56. Zlatan, Cognitive Semiotics.

57. Susan Petrilli and Augusto Ponzio, 'Semiotics Today. From Global Semiotics to Semioethics, a Dialogic Response,'Signs 1, (2007): 29-127.

58. Hoffmeyer, Signs of Meaning.

59. Deely, 'The Impact of Semiotics'.

60. Ibid.

61. Steve Mackey, 'Semiotic, Rhetoric and Democracy,' Cosmos and History: The Journal of Natural and Social Philosophy 8, no. 1 (2012); Deely, The Impact of Semiotics.

62. http://natureisspeaking.org

63. Mackey, Semiotic, Rhetoric and Democracy.

64. The Holy Qur'an.

65. John Kay, Other People's Money: Master of the Universe or Servants of People (London: Profile Books Ltd, 2015).

66. K. L. O'Halloran, 'Multimodal Discourse Analysis', in Companion to Discourse, ed. K. Hyland and B. Paltridge (London and New York: Continuum, 2011); K. L. O'Halloran and B. A. Smith, 'Multimodality and Technology', in The Encyclopedia of Applied Linguistics, ed. Carol A. Chapelle (New Jersey: Wiley-Blackwell, 2012); K. L. O'Halloran, 'Multimodal Analysis and Digital Technology', in Interdisciplinary Perspectives on Multimodality: Theory and Practice, ed. A. Baldry and E. Montagna, Proceedings of the Third International Conference on Multimodality, Available at: http://multimodal-analysis-lab. org/_docs/Multimodal\%20Analysis\%20and\%20Digital\%20Technology.pdf (Accessed February 24, 2017).

67. Kamali, 'Reading the Signs', 163.

68. See Martin Lings, 'The Symbolism of the Letters of the Alphabet', in A Sufi Saint of the Twentieth Century: Shaikh Ahmad al- 'Alawì: His Spiritual Heritage \& Legacy (Cambridge: Islamic Texts Society, 1993).

69. See Netton, 'Allah Transcendent'. 